\title{
ОПРЕДЕЛЕНИЕ КОНЦЕНТРАЦИИ ГИДРОКСИЛЬНЫХ ГРУПП НА ПОВЕРХНОСТИ ОКСИДОВ АЛЮМИНИЯ, ГАЛЛИЯ И ИНДИЯ
}

\author{
(Представил О. Эйзен)
}

Поверхность оксидов металлов III A группы периодической системы представляет интерес с точки зрения зависимости адсорбционных процессов от состояния гидратного покрова упомянутых оксидов. Выявление этой зависимости приобретает особое значение в связи с наличием оксидов алюминия, галлия и индия на поверхности многих полупроводниковых материалов типа $\mathrm{A}^{\amalg} \mathrm{B}^{\mathrm{V}}$, электрофизические параметры которых во многом определяются именно состоянием гидратного покрова поверхностных оксидов.

В данной работе исследовались возможности определения количества адсорбированной воды и гидроксильных групп на поверхности оксидов алюминия, галлия и индия.

По известным нам данным, в интересующем нас аспекте до сих пор исследовались только разные модификации оксида алюминия. Можно предположить, что методика исследования оксидов галлия и индия металлов, входящих с алюминием в одну подгруппу III группы периодической системы, должна быть аналогичной. В то же время положение алюминия рядом с кремнием позволяет использовать обширные исследования и в области двуокиси кремния - кремнезема как основы силикагеля и компонента алюмосиликатов.

Один из первых методов определения содержания адсорбированной воды и гидроксильных групп - определение по потере веса при прокаливании - не позволяет дифференцировать поверхностную и внутриглобульную, а также физически адсорбированную и структурную воду. В основу химических методов положены реакции замещения водорода в гидроксильных группах. Однако эти реакции с участием таких соединений, как $\mathrm{AlCl}_{3}, \mathrm{BCl}_{3}, \mathrm{~B}_{2} \mathrm{H}_{6}, \mathrm{SOCl}_{2}, \mathrm{TiCl}_{4}, \mathrm{Si}\left(\mathrm{CH}_{3}\right)_{x} \mathrm{Cl}_{4-x}$, часто протекают не до конца или осложняются побочными реакциями, из-за чего нарушается стехиометрия, а следовательно, и не исключается возможность существенного искажения результатов определений $\left[{ }^{1-3}\right]$. Только при использовании металлоорганических соединений обусловливается полное завершение реакции с выделением эквивалентного количества газа, однако при этом приходится работать с абсолютным эфиром. Наиболее достоверные результаты дает метод дейтерообмена с масс-спектрометрическим выходом, но его применение ограничивают методические сложности.

Метод ИК-спектроскопии позволяет дифференцировать гидроксильные группы на свободные (активные) и на связанные взаимной водородной связью, а также различать гидроксильные группы и молекулярно адсорбированную воду. Но в случае оксида индия спектральный метод не применим из-за нахождения спектра поглощения в области, не поддающейся регистрации. 
При выборе подходящего метода анализа нами ставилась цель устранить основной недостаток многих методов, т.е. избежать термообработки и вакуумирования образцов для удаления адсорбированной воды. В результате сравнения ранее описанных методов наиболее подходящими для нашей задачи были признаны два - металлоорганический и ионообменный $\left[{ }^{4-7}\right]$.

Металлоорганический метод позволяет анализировать продукт замещения на содержание магния в исследуемом оксиде. Совмещая реакцию Гриньяра с удалением адсорбированной воды путем промывания абсолютным эфиром, удается избежать тем самым стадии термообработки $\left.{ }^{4}\right]$.

Метод ионообмена $\mathrm{Ca}^{2+}$ основан на разделении процесса взаимодействия исследуемого вещества с раствором $\mathrm{Ca}(\mathrm{OH})_{2}$ на две реакции - быструю реакцию ионного обмена, которую лимитирует диффузия, зависящая от степени дробления и радиуса пор, и реакцию образования новой фазы, которую лимитирует скорость растворения исследуемого вещества [5-7]. При отсутствии диффузионных препятствий равновесному состоянию ионного обмена соответствует на кинетической кривой начало линейного участка, экстраполяция которого до оси ординат дает предельное значение величины ионообменного поглощения $\mathrm{Ca}^{2+}$.

Кинетику ионного обмена в данном случае исследовали статистическим методом, т. е. отбирая пробы и строя кинетические кривые по данным количественного анализа [ $\left.{ }^{8}\right]$.

При нонообменном методе надо учитывать возможность эквивалентного и эквимолярного поглощения ионов кальция относительно содержания гидроксильных групп:

$$
\begin{gathered}
2(-\mathrm{OH})+\mathrm{Ca}(\mathrm{OH})_{2} \rightleftharpoons(-\mathrm{O})_{2} \mathrm{Ca}+2 \mathrm{H}_{2} \mathrm{O}, \\
-\mathrm{OH}+\mathrm{Ca}(\mathrm{OH})_{2} \rightleftharpoons-\mathrm{OCaOH}+\mathrm{H}_{2} \mathrm{O} .
\end{gathered}
$$

Ионы кальция поглощаются преимущественно эквимолярно при наличии определенного расстояния между соседними гидроксильными группами, с которого иону кальция становятся недоступными одновременно две гидроксильные группы. В результате ионообменное поглощение $\mathrm{Ca}^{2+}$ в эквивалентных единицах превышает содержание ОН-групп вдвое.

\section{Әкспериментальная часть}

Реактивы: 1) обезвоженный $\mathrm{P}_{2} \mathrm{O}_{5}$ и $\mathrm{Na}$ абсолютный этиловый эфир; 2) магниевая стружка; 3) свежеперегнанный метилиодид (х. ч.); 4) $0,01 \mathrm{M}$ раствор трилона Б; 5) приготовленный по методике [ ${ }^{\text {] }}$ буферный раствор; 6) 0,4\%-ный спиртовой раствор эриохрома черного Т (хромогена черного ЕТ-00); 7) $1 \%$-ный раствор соляной кислоты (х.ч.); 8) $1 \%$-ный раствор хлористого аммония (х. ч.); 9) $25 \%$-ный раствор водного аммиака (х. ч.); 10) синтезированный по методике [10] реактив Гриньяра $(0,5 \mathrm{M})$.

Анализируемые вещества: оксид алюминия (ч.д.а.), оксид галлия (о. ч.), оксид индия (о. ч.).

Удельные поверхности анализируемых веществ, определенные методом БЭТ по низкотемпературной адсорбции азота, составляют 60,1 , 14,9 и $3,3 \mathrm{~m}^{2} / \mathrm{r}$ соответственно.

Навеску (0,3 г) анализируемого оксида помещали в специальный сосуд, осуществляли обезвоживание промыванием абсолютным эфиром, а затем реакцию Гриньяра по методике [4]. Навеску $(0,1-0,2$ г) высушенного соединения помещали в стакан на 50 мл и разлагали, 


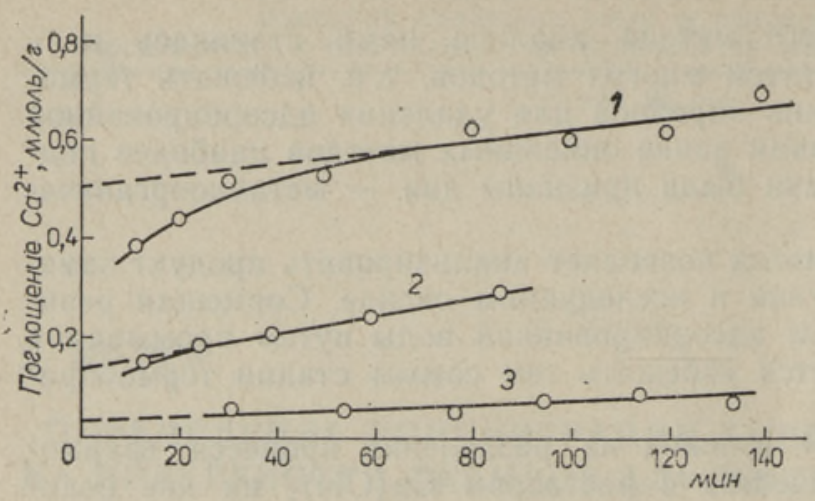

Поглощение нонов кальция на поверхности оксидов алюминия $(1)$, галлия (2) и индия (3).

добавляя 10 мл дистиллированной воды и 5 мл $1 \%$-ного раствора $\mathrm{HCl}$. Затем выпаривали содержимое почти досуха, добавляли 10 мл воды и отфильтровывали раствор в стакан на 200 мл, перенося частицы оксида количественно на фильтр и тщательно ополаскивая стенки стакана и фильтр сначала горячей $1 \%$-ной $\mathrm{HCl}$, потом горячей дистиллированной водой. Полученный фильтрат нагревали до кипения и осаждали соответствующий гидроксид алюминия, галлия и индия добавлением концентрированного водного аммиака до $\mathrm{pH} 6-7$. После 5-10-минутного отстаивания осажденный гидроксид отделяли на том же фильтре, который использовали раньше, и собирали фильтрат в колбу для титрования. Осадок промывали 3-4 раза горячим $1 \%$-ным раствором хлористого аммония.

В фильтрате, соединенном с промывными водами, комплексонометрически определяли содержание магния, эквивалентное количеству гидроксильных групп, по методике []. Содержание оксида на фильтре находили после озоления фильтра и прокаливания весовым методом.

Определение количества гидроксильных групп методом ионообмена $\mathrm{Ca}^{2+}$. Реактивы: 1) 0,015 M раствор гидроксида кальция (ч.); 2) 0,025 M раствор соляной кислоты (х. ч.); 3 ) 0,1\%-ный спиртовой раствор фенолфталеина.

K 2 г образца в 1-литровой трехгорлой колбе, снабженной мешалкой, трубами для ввода и отвода газа $\left(\mathrm{N}_{2}\right.$ или $\left.\mathrm{Ar}\right)$ и устройством для отбора проб, доливали в соответствии с теоретической оценкой $300-500$ мл раствора $\mathrm{Ca}(\mathrm{OH})_{2}$ для обеспечения снижения исходной концентрации раствора на $10-20 \%$ за 2 ч. Зафиксировав начало реакции, отбирали через определенные промежутки времени пробы, в которых титрованием с $\mathrm{HCl}$ по фенолфталеину определяли концентрацию $\mathrm{Ca}(\mathrm{OH})_{2}$. Длительность опыта не превышала 2 ч. На основании полученных данных стронли кинетические кривые. Экстраполируя линейный участок кривой до оси ординат, можно находить количество $\mathrm{Ca}^{2+}$, взаимодействующего c поверхностными гидроксильными группами. В случае, если поглощение $\mathrm{Ca}^{2+}$ эквивалентно содержанию ОН-групп, оно определяется графически, как это показано на рисунке.

\section{Обсуждение результатов}

Определение концентрации гидроксильных групп по двум описанным методикам дало практически совпадающие результаты (таблица), что говорит о применимости металлоорганического и ионообменного методов для исследования гидроксильного покрова оксидов металлов III А группы. 
Содержание гидроксильных групп на поверхности оксидов алюминия, галлия и индия, мкмоль $\cdot \mathbf{m}^{-2}$

\begin{tabular}{l|c|c|c}
\hline \multirow{2}{*}{ Метод } & \multicolumn{3}{|c}{ Оксид } \\
\cline { 2 - 4 } & $\mathrm{Al}_{2} \mathrm{O}_{3}$ & $\beta-\mathrm{Ga}_{2} \mathrm{O}_{3}$ & $\mathrm{In}_{2} \mathrm{O}_{3}$ \\
\hline \multirow{2}{*}{\begin{tabular}{l|c|c} 
Металлоорганический \\
Ионообменный
\end{tabular}} & 8,8 & 11,4 & 15,2 \\
& 8,8 & 10,8 & 15,2
\end{tabular}

Пять ОН-групп на $100 \AA^{2}\left(8,8\right.$ мкмоль $\left.\mathrm{M}^{-2}\right)$ в случае $\mathrm{Al}_{2} \mathrm{O}_{3}$ не препятствует их эквимолярному замещению ионами $\mathrm{Ca}(\mathrm{OH})^{+}$, а тем более эквивалентному замещению ионами $\mathrm{Ca}^{2+}$, имеющими радиус $1,04 \AA$. При большей плотности ОН-групп эквивалентное замещение становится более вероятным из-за меньших пространственных препятствий. Результаты настоящей работы показывают, что при данной плотности происходит эквивалентное замещение $\mathrm{OH}$-групп ионами $\mathrm{Ca}^{2+}$. В противном случае поглощение последних в эквивалентных единицах имело бы величину, двукратно превышающую содержание ОН-групп.

Представляет интерес сравнить результаты наших определений с литературными данными, которые, как уже отмечалось, относятся только к оксиду алюминия (имеются в виду исследуемые оксиды). Из данных, основанных на кристаллографических расчетах, приведено прежде всего содержание ионов кислорода в поверхностном монослое $\alpha-\mathrm{Al}_{2} \mathrm{O}_{3}$ и $\gamma-\mathrm{Al}_{2} \mathrm{O}_{3}$, которое при предельном гидроксилировании совпадает с концентрацией гидроксильных групп: $19 \mathrm{OH} / 100 \AA^{2}\left[{ }^{11}\right]$ $\left(31,6\right.$ мкмоль $\left.\cdot \mathrm{M}^{-2}\right)$ и $12,5 \mathrm{OH} / 100 \AA^{2}\left[{ }^{12}\right]\left(20,8\right.$ мкмоль $\left.\cdot \mathrm{M}^{-2}\right)$ соответственно. На основе сравнения этих данных с полученными при термообработке сделан вывод о полном удалении физически адсорбированной воды путем вакуумирования образца при $200-250{ }^{\circ} \mathrm{C}\left[{ }^{13}\right]$. Конденсация гидроксильных групп с выделением хемосорбированной воды начинается с температур порядка $100-200^{\circ}\left[{ }^{13}\right]$ и завершается полным дегидроксилированием поверхности при $1100^{\circ}\left[{ }^{14}\right]$. Влияние термообработки на дегидратацию и дегидроксилирование поверхности оксидов металлов III А группы подробнее изучено в [ $\left.{ }^{15}\right]$.

При сравнении концентрации гидроксильных групп на поверхности оксида алюминия, полученной нами, - 8,8 мкмоль м $^{-2}$, с литературными данными - 4,2-7,5 мкмоль м $^{-2}[13,14,16-19]$, соответствующими вакуумированию при температуре до $500^{\circ}$, напрашивается вывод о частичном дегидроксилировании (до $50 \%$ ) поверхности $\mathrm{Al}_{2} \mathrm{O}_{3}$ в этих условиях. Этот вывод предполагает полное соответствие приведенных данных истинной концентрации поверхностных ОН-групп, исключая координативно связанные молекулы воды.

По литературным данным, координативно связанная вода выделяется вакуумированием при температуре $400^{\circ}$. Отсюда следует, что найденная нами концентрация ОН-групп на поверхности оксида алюминия $\left(8,8\right.$ мкмоль $\left.\cdot \mathrm{M}^{-2}\right)$ правильна и что использованные нами методы исключают возможность учета координативно связанной воды. Этот вывод подтвердился обнаруженной в ходе работы длительной регидратацией поверхности $\mathrm{Al}_{2} \mathrm{O}_{3}$ после ее обезвоживания абсолютным эфиром - концентрация активного водорода на поверхности оставалась практически неизменной в течение нескольких суток. Такое явление можно объяснить вытеснением координативно связанных молекул воды в процессе адсорбции молекулами эфира, имеющими более электропозитивные атомы кислорода. В результате центры адсорбции блокируются, и поверхность регидратируется по мере медленной десорбции эфира. Хорошее согласие литературных данных, полученных методами, 
использованными нами, с данными, полученными другими методами, говорит тоже в пользу достоверности вышеприведенных результатов.

Итак, результаты данной работы показывают, что приводимое в литературе значение $4,2-7,5$ мкмоль м $^{-2}$ для концентрации ОН-групп на поверхности оксидов алюминия, является не только не завышенным, как считалось вследствие отнесения прочно связанных с поверхностью $\mathrm{Al}_{2} \mathrm{O}_{3}$ молекул воды к структурным гидроксилам [19], но даже заниженным, поскольку реальная поверхность всегда непредельно гидроксилирована (предельно гидроксилированная поверхность $\gamma$-оксида алюминия

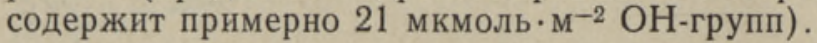

\section{Выводы}

1. Ионообменное поглощение ионов кальция поверхностью оксидов алюминия, галлия и индия происходит эквивалентно относительно содержания гидроксильных групп.

2. Координативно связанная вода не учитывается использованными методами, поскольку она удаляется при промывании абсолютным эфиром.

3. При вакуумировании образцов $\mathrm{Al}_{2} \mathrm{O}_{3}$ до температуры $500^{\circ}$ происходит частичное (до $50 \%$ ) дегидроксилирование поверхности.

\section{ЛИТ Р Р Т УРА}

1. Стрелко В. О механизме дегидратации и регидратации поверхности дисперсных кремнеземов. - Адсорбция и адсорбенты, 1974, вып. 2, 65-75.

2. Armistead, C., Tyler, A., Hambleton, F., Mitchell, S., Hockey, J. The surface hydroxylation of silica. - J. Phys. Chem., 1969, 73, 3947-3953.

3. Hombek, R., Kijeriski, J., Malinovski, S. Ocena stosowanych metod oznaczania grup wodorotlenowych na powierzchniach katalizatorów heterogennych. Przem. Chem., 1978, 57, 568-573.

4. Рослякова $H$., Алесковский $B$. Определение концентрации гидроксильных групп на поверхности силикагеля. - Ж. прикл. хим., 1966, 39, № 4, 795-802.

5. Плачинда А., Чертов B., Неймарк Й. Взаимодействие силикагелей разной пористой структуры с раствором Са $(\mathrm{OH})_{2}$. - Укр. хим. ж., 1965, 31, № 6, $567-573$.

6. Чертов B., Джамбаева Д., Плачинда А., Неймарк И. Гидроксильные группы на поверхности и внутри глобул силикагелей, полученных из гидротермально обработанных гидрогелей. - Ж. физ. хим., 1966, 40, № 5, 520-525.

7. Белоус А., Книгавко Н., Деринг Н. Определение количества гидроксильных групп на поверхности кремнеземов. - Тр. Науч. и проект. ин-та основной химии, 1976, вып. 42, 69-74.

8. Полянский $H$., Горбунов $Г$., Полянская $H$. Методы исследования ионитов. М., $1976,167$.

9. Приибил Р. Комплексоны в химическом анализе. М., 1955, 55-56.

10. Гаттерман Л., Виланд Г. Практические работы по органнческой химин. М., 1948, 97.

11. Wade, W., Hackerman, $N$. Heats of immersion. IV. The aluminawater system variations with particle size and outgassing temperature. - J. Phys. Chem., 1960, 64, 1196-1199.

12. Peri, J. Infrared and gravimetric study of the surface hydration of $\gamma$-alumina, J. Phys. Chem., 1965, 69, 211-219.

13. Hendrikson, B., Pearce, D., Rudham, R. Heats of adsorption of water on $\alpha$ - and $\gamma$-alumina, - J. Catal., 1972, 24, 82-87.

14. Morimoto, T., Shiomi, K., Tanaka, H. The heat of immersion of aluminium oxide in water. - Bull. Chem. Soc. Jap., 1964, 37, 392-395.

15. Вuйра Я. Влиянне термообработки на состояние гидратного покрова окислов алюмнния, галлия и индия. - Изв. АН ЭССР. Хим., 1985, 34, № 1, 69-71.

16. Sato, M., Kanbayashi, T., Kobayashi, N., Shima, Y. Hydroxyl groups on silica, alumina, and silica-alumina catalysts. - J. Catal., 1967, 7, 342-351. 
17. Naono, H., Kadota, T., Morimoto, $T$. Surface water content of metal oxides. II. Measurement of samples containing pores: silica, alumina, and silica-alumina. - Bull. Chem. Soc. Jap., 1975, 48, N 4, 1123-1126.

18. Nondek, L. Determination of hydroxyl groups and/or water on the surface of oxide catalysts by a pulse chromatographic method. - React. Kinet. Catal. Lett., $1975,2, \mathrm{~N} 3,283-289$.

19. Чуйко А., Круглищкий Н., Шиманский А., Мащенко В. Исследование химии поверхности высокодисперсной окиси алюминия методом ИК-спектроскопии. Ж. физ. хим., 1975,49 , № $2,435-439$.

Ннститут термофизики и электрофизики Академии наук Эстонской ССР

Поступила в редакцию 6/VII 1983

\section{J. VIIRA}

\section{HUDROKSUOLRUHMADE KONTSENTRATSIOONI MÄÄRAMINE ALUMIINIUM-, GALLIUM- JA INDIUMOKSIIDI PINNAL}

On määratud hüdroksüülrühmade kontsentratsioonid perioodilisuse süsteemi III A rühma metallide oksiidide pinnal, kasutades Grignard'i reaktsiooni ja ioonvahetusmeetodit. Tulemuste praktilise kokkulangevuse põhjal on tehtud järeldus nende meetodite kasutatavuse kohta kõnealusel eesmärgil. Võrdlusest kirjandusandmetega tulenenud küsimust uuritavate oksiidide pinna dehüdratatsiooni ja dehüdroksüleerimise tingimuste kohta on käsitletud varem avaldatud lühiteates [ ${ }^{15}$.

\section{J. VIIRA}

\section{DIE BESTIMMUNG DER KONZENTRATION DER HYDROXYLGRUPPEN AUF DER OBERFLÄCHE DES ALUMINIUM-, GALLIUM- UND INDIUMOXIDES}

Es wurde die Konzentration der Hydroxylgruppen auf der Oberfläche der Oxide der Gruppe III A des Periodensystems festgestellt, wobei 1) die Grignard-Reagenz und 2) der Ionenaustausch gebraucht wurden. Da die Resultate in beiden Fällen praktisch übereinstimmen, ist die Anwendung dieser beiden Methoden zu dem gegebenen Zweck möglich.

Mit dem beim Einblick in die Literaturangaben entstandenen Problem der Dehydratation und des Dehydroxylierens der Oxidoberfläche befaßt sich unser Kurzbericht [15].

Es ergibt sich, daB das koordinativ verbundene Wasser bei den verwandten Methoden mit dem absoluten Diäthyläther ausgeschieden wird. Das Aluminiumoxid wird durch Vakuumieren bei $500^{\circ} \mathrm{C}$ zum Teil (bis zu 50 Prozent) dehydroxyliert. 